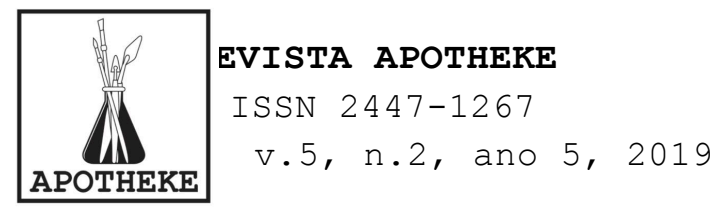

\title{
O Desenho-Escritura de Ana Hatherly e Mira Schendel
}

\author{
Marta Martins (CEART-UDESC)
}

\section{RESUMO}

A arte contemporânea é um regime de saber que tem se tornado cada vez mais permeável, portanto as contaminações entre disciplinas e meios é uma recorrência. Os desenhos de Mira Schendel e Ana Hatherly que se fundem. Com seus textos e escrituras são exemplos do diálogo entre narrativas, memórias e diários que expandem o processo plástico. O presente artigo aborda o desenho das duas artistas e sua relação com a escrita.

PALAVRAS CHAVE: Desenho; Escrita; Artes Visuais; Narrativas; Memória.

Ao longo da minha prática como artista, docente e pesquisadora em desenho, percebi três vertentes conceituais em torno desse meio. A primeira delas, diz respeito a uma concepção utilitária do mesmo, onde o desenho é visto como uma ferramenta de trabalho do artista a se realizar de verdade em formatos vistos ainda hoje em dia, como mais nobres e perenes tais como a pintura, a escultura e a gravura. Uma segunda concepção artística e teórica, de cunho modernista, diz respeito a ideia de que o desenho é um meio expressivo poderoso, autônomo e autossuficiente, com valor intrínseco em si mesmo. A terceira ideia, contemporânea, é a concepção de um desenho que pode se efetivar por meio de um desenho atravessado por outras disciplinas artísticas, onde ele se funde com o espaço circundante e com outras categorias.

Sem dúvida há que se prestar o devido respeito aos acaso e ao acidental no desenho e reconhecê-lo como expressão do irreversível. Nada como o desenho na obra de um artista para identificar algo extremamente pessoal e singular, sua marca e pegada no mundo, um pequeno rastro.

DOI : $10.5965 / 24471267522019029$

http://dx.doi.org/10.5965/24471267522019029 
Pode se ensinar algumas regras básicas em termos de uso dos materiais e instrumentos próprios ao ato de desenhar algumas técnicas de utilização dos mesmos, mas não se pode ensinar personalidade nem estilo a quem pretende se dedicar seriamente ao desenho. A informação sobre arte é valiosa, ver a produção de desenhos ao longo da história e em diversos lugares, tudo isso aprimora o desenvolvimento de um domínio particular sobre o meio.

A concepção se revela em procedimentos característicos do processo pessoal do artista quando desenha: seja por linhas de contorno ou através de manchas, ele geralmente aponta para uma assinatura intransferível e única. Plenos dessas singularidades, os desenhos de Ana Hatherly e Mira Schendel, que se fundem com seus textos e escritos, são exemplos do diálogo entre narrativas, memórias e diários que expandem o processo plástico.

A arte contemporânea é um campo no qual a membrana entre as disciplinas e meios tem se tornado inteiramente permeável, portanto o campo das "impurezas" e das contaminações na cena artística contemporânea é uma recorrência. Segundo Paulo Pires do Vale que foi curador da exposição Ana Hatherly e o Barroco, "Num jardim feito de tinta", na Fundação Gulbenkian, a artista, "como estudiosa do barroco se deixaria contaminar em sua obra pelas categorias barrocas de labirinto, tempo, alegoria e metamorfose." (Pires do Vale: 2017)

Tal como na obra de Mira Schendel, a palavra escrita avança na poética gráfica da artista portuguesa como um modo de interrogação de mundo. A palavra Paz num rolo que lembra os ensinamentos da Torá judaica num trabalho de Hatherly me parece um bom ponto de união entre os preceitos das duas artistas. 


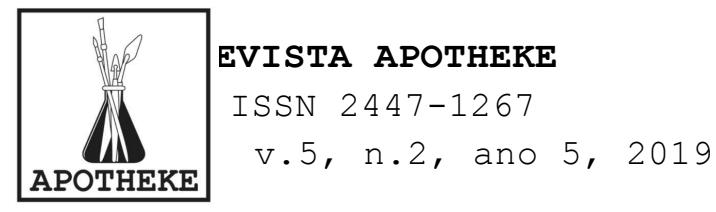

$\mathrm{Na}$ produção textual e visual de Ana Hatherly há um percurso singular pela interioridade da escrita para concluir que esta "nunca foi senão representação: imagem". (Batel, : 2010) A artista percorre uma espécie de arqueologia da língua, viagem que leva até as origens dos signos e a caligrafia oriental arcaica que inscreve fisicamente com todo - corpo que se move e se inscreve no indizivel da escritaimagem. 

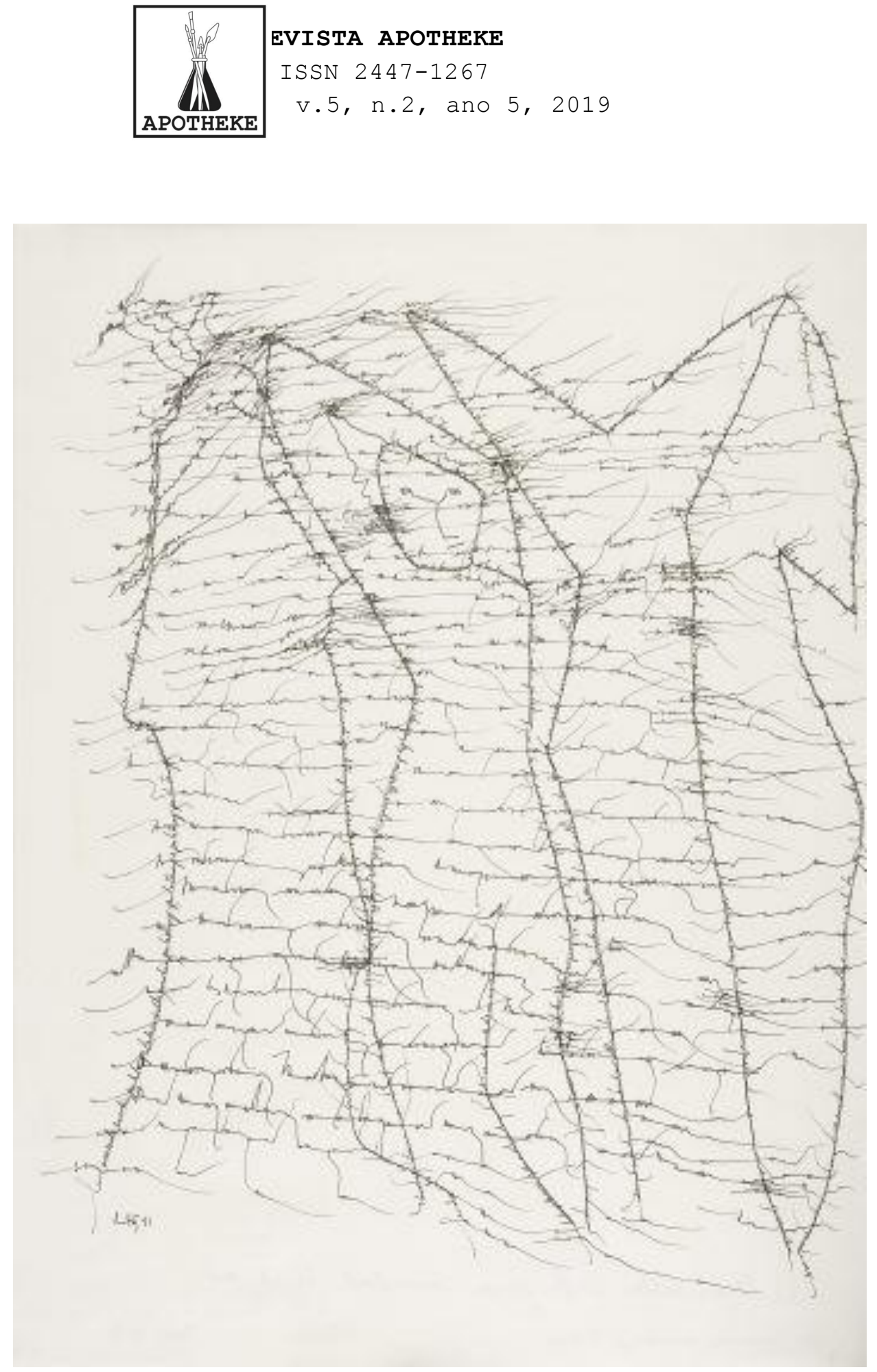

Ana Hatherly: Les demoiselles D"Avingnon invaded by time. Canetasobre papel. 1991

(coleção Calouste Gulbenkian) 


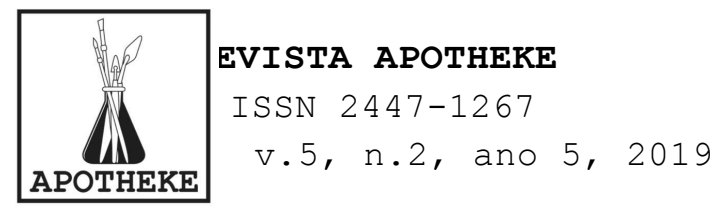

Entre outubro de 2017 e Janeiro de 2018, houve a exposição retrospectiva "Num Jardim Feito de Tinta", com pinturas e ensaios da artista e escritora, que explorou a ligação da obra da criadora ao Barroco, na Fundação Calouste Gulbenkian." ". "São muitas as portas de entrada neste edifício, pois também foram variadas as declinações da obra de Ana Hatherly: nos ensaios e investigação acadêmica; na poesia e na prosa; nos desenhos, nas colagens, nas performances, nos filmes, nos programas televisivos", lê-se no texto de apresentação do catálogo da retrospectiva na Fundação Gulbenkian. (Pires do Vale, 2017) É neste "labirinto onde tudo gira à volta da escrita", que é apresentado um jardim feito de tinta, onde a artista reinventa o mundo caminhando por entre signos. O labirinto, um emblema do barroco, retorna nas reflexões e na obra de Hatherly. Na poesia Ana Hatherly efetiva seu interesse pela estética barroca quando inicia um percurso multifacetado voltado para a "conceitualização do processo criador" e para a interioridade da escrita. Durante os anos 60 persegue os valores plásticos da escritura em poemas-visuais e ou poemas-figurativos, afastando-se do concretismo e descobrindo as raízes remotas da visualidade da língua. Segundo Joana Batel, (Batel, 2018):

\footnotetext{
Num percurso que vai da vanguarda - no poema Un Coup de Dès (1897) de Stéphane Mallarmé (1842-1898) ou nos caligramas de Guillaume Apollinaire (1880-1918) - até às experiências caligráficas orientais e aos labirintos anagramáticos do barroco, Ana Hatherly assinala os rastos da evolução e reinvenção da escrita. Ernesto Melo e Castro chamou-lhe «barroco intuitivo», mas o programa iniciado nos Mapas da imaginação e da memória(1973) evidencia a cientificidade das suas pesquisas, que
}

\footnotetext{
2 Com curadoria de Paulo Pires do Vale, em colaboração com Nuno Vassallo e Silva, a exposição compunha um percurso a partir de categorias essenciais do Barroco.o "Mundo como Labirinto", a importância do "Lúdico", a "Vida como Nada diante da Morte", a "Alegoria e a folia da Interpretação", o "Diálogo oblíquo entre pintura e poesia" e a "Metalinguagem" da obra de arte constituem os diferentes núcleos da mostra dedicada à criadora de "Volúpsia", "Interfaces do olhar" e das mais de quatro centenas de "Tisanas."
} 


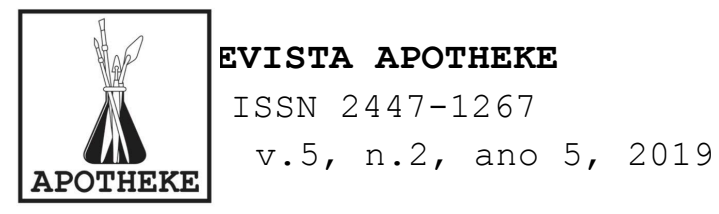

culminam na edição de vários ensaios sobre a arte dos séculos XVII e XVIII. Ao mesmo tempo, começa uma longa série de poemas em prosa, ardilosas construções narrativas que mesclam diferentes estruturas discursivas, como a fábula ou a alegoria, e a que dá o nome de Tisanas. Estes textos curtos e desconcertantes são marcados por uma alquimia da escrita que põe à prova todas as certezas, assemelhando-se aos enigmas veiculados pelo Budismo Zen, mais conhecidos por koans.

A linha do desenho é análoga ao fio da tecelagem e possui relação com a escrita ou, com a própria narrativa. O trabalho das duas artistas têm em comum a questão do desenho associado a letra, a palavra escrita. Porém é uma escrita fragmentada, onde a impossibilidade de narrar algo completo, falha. a tecelagem e o processo narrativo, fundem-se na palavra trama. Da forte tradição de mulheres fiandeiras e tecelãs, oriunda da Grécia, iria surgir todo um mecanismo literário onde a tradição narrativa é fortemente associada aos gestos artesanais da costura, do bordado e da tecelagem. Lembremos a figura de Penélope, famosa por sua astúcia, na espera do retorno de Ulisses, ao tecer o manto que lhe afastou os pretendentes indesejados. Mas Penélope, cujo próprio nome já destina sua vocação, já que é oriundo de pene, que em grego significa o fio próprio para tecer, tornou-se, sobretudo, um emblema do impasse do criador frente à resolução final da obra, diante das possibilidades infinitas que a linguagem oferece.

- artista, num um processo semelhante ao de Penélope de tecer e destecer, lida com uma procrastinação voluntária, ao não resolver todos os enigmas que sua obra vai constituindo, muitas vezes isso é decorrente de uma ativação constante e desafiadora de sua própria capacidade criativa.

Relembrando um pouco destas figuras femininas da mitologia, aonde os fios literalmente conduzem a narrativa, há as mitológicas Parcas, tecelãs dos destinos humanos, onde o 
desenrolar das vidas são o motivo que decora o tecido. E Ariadne, que forneceu a Teseu a chave da astúcia para vencer o Minotauro, através de um fio. Há ainda Pandora, que além de possuir a fiança da caixa que não deveria ser aberta, foi a primeira mulher tecelã, e que aprendeu a arte da fiação com a própria deusa Atena. E por fim, a própria Aracnê, que após desafiar a deusa Atena nas artes da tapeçaria, termina por ser transformada em aranha, o animal que por excelência tece, terrível e belamente, a malha mortuária para sua presa.

Em todos estes casos, há uma ideia de astúcia e ardil feminino no processo têxtil, que aparece conjugado à transmissibilidade da palavra. É desde esse ponto que a tradição feminina de lidar com os fios, nos levaria à narrativa processada como fio que separa a vida da morte, pela mulher que conta histórias. À narrativa suspensa por um fio, pertence Sherazade e a linhagem dos narradores que como ela, e através do poder encantatório da palavra, tentam driblar a morte. A reconquista diária da vida, nos fala, também, dos frágeis, tênues mecanismos dos meios da linguagem, que precisa vencer constantemente a ameaça de sua dissipação.

A reflexão da poeta e ensaísta argentina Tâmara Kamenszain, ao dizer que a escritura e o silêncio se reconhecem um ao outro, no caminho que os põe à parte da fala; e que a mulher,"silenciosa por tradição", está próxima da escritura. Em seu argumento, o acesso feminino à fala teria nascido, balbuciante e acanhada, do sussurro e dos cochichos, apesar do fato de terem as mulheres, paradoxalmente, recebido dos homens, a alcunha de "muito conversadeiras". (Kamenszain:

2002). Essa conversação não tendo tido atuação decisiva na "marcialidade" dos discursos de poder, não seria outra coisa que : 


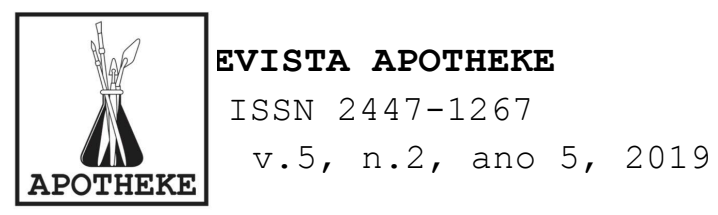

\begin{abstract}
Esa enmarañada mezcla de niveles discursivos cuyo decir, como objeto, es la nada. Susurrante plática de mujeres, fue creando una cadena irrompible de sabiduría por transmisión oral, que nunca quedó recogida en libros. (Kamenszain: 2002)
\end{abstract}

Há um reverso que habita na escritura, que baseia sua preservação por via da transmissão oral. Kamenszain relaciona, a partir desta premissa, que a produção de alguns escritores, deve sua estrutura ao aspecto feminino e maternal da escritura, pois, "da mãe se aprende a escrever", sendo ela a mestra por excelência de escritores, já que é ela que imprime ao lar, aquele sem sentido prazenteiro da palestra". (Kamenszain: 2002) A ensaísta começa por observar que Góngora não aprendeu a escrever através de manuais de versificação, mas que sua poesia, "receita milenar de avó", procederia da prática reiterativa oriunda dos cochichos das regras culinárias. Através de um depoimento de uma irmã de Lezama Lima, que recorda o ambiente cotidiano da família, a ensaísta enfatiza o importante papel que as as mulheres iriam ter em sua obra, já que elas investiam grande parte do tempo em incessantes diálogos, que eram somente interrompidos para prosseguirem nas tarefas do dia-a-dia, e ao qual retornavam, fiando-os com aperfeiçoada técnica, a formar como que a marca cultural das crianças da família. De modo que essa rica tradição oral serviu para enriquecer o inconsciente do poeta, que anos mais tarde, os iria remontando, submetendo-os à sua invenção. O que ao longo do tempo os foi como incubando dentro de sua obra já que mãe imprime o espaço artesanal ao lar, na obsessão vazia das tarefas diárias:

Coser, bordar, cocinar, limpiar, cuántas maneras metafóricas de decir escribir. Ya es casi parte del sentido común comparar al texto con un tejido, a la construcción del relato con una costura, al modo de adjetivar un poema con la acción de bordar. Tras el supuesto de que las mujeres, dedicadas al detalle, pierden mucho tiempo, las grandes compañias de limpieza prefieren contratar hombres. Son ellas las que ven el 


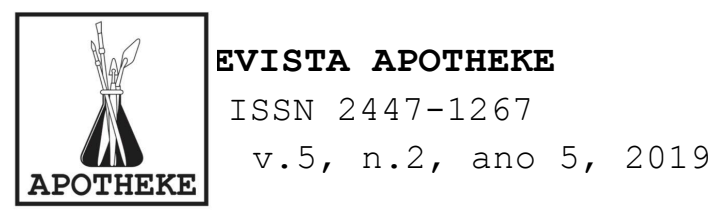

polvo escondido detrás de los objetos y las que se detienen en él. En esa lenta práctica de ir descubriendo lo que otros no ven, perfeccionan su oficio. Del mismo modo, cuando el ojo que relee lo escrito pierde tiempo encontrando suciedad en el detalle, trabaja como mujer. Cepillar un texto, pasarle el plumero, son metáforas que nacieron en la tarea domestica y a ella deben su obsesividad artesanal. (Kamenszain: 2002)

Kamenszain atribui à falta de demanda de que as mulheres escrevessem o fato de que incubassem o sintoma literário, desviando-o para as tarefas domésticas e a conversação. O sintoma, porém teria ido habitar em seus filhos, e assim, teriam surgido algumas das obras assinadas por homens, dotados, porém, de uma invisível co-escritura feminina. A memória feminina, incorporada nas conversas, encontrou seu lugar de registro escrito nos diários, cartas e receitas:

Proust, como tantos otros artesanos del bordado y del
tejido, es hijo de la escritura femenina. Interlocutor
de abuelas, madres, sirvientas, lanza rodar el diario
intimo, lo legaliza, lo vuelve literatura. aunque para
ello era necesario que le imprimiera una firma masculina
- ley y hombre encuentran su sintesis perfecta en la
firma - también era necesario que permaneciera sentado,
como las hermanas Bronté imaginadas por Virginia Wolf,
en medio de la sala de estar. Para la Wolf es en medio
de esse ámbito de pláticas, de cruces, de trabajos
domésticos, donde se teje la historia familiar.
Charlotte y Emily, sin cuarto propio, acumulaban, desde
el lugar colectivo de la casa, la maeria de la
novela.Pero así como Proust pidió prestado a la mujer
ese lugar de la casa, las Bronté, para publicar para
hacerse públicas-, pidieron prestadas al hombre la
firma, la legalidad." (Kamenszain: 2002) No domínio das pequenas tarefas cotidianas, há uma prática de escritura sem grafia e sem marca, associada à fragilidade dos fios da vida cotidiana, mantida pela ordem do feminino. Este universo, alimentado pelo sintoma da escritura, teria então se tornado a sobrevivência da fatura artesanal e narrativa, do fio de união entre a mão e a palavra. que se encontravam completamente esgarçados na cena fragmentária da modernidade benjaminiana, e nesse sentido, são a contra-face daquela experiência que havia sido considerada 


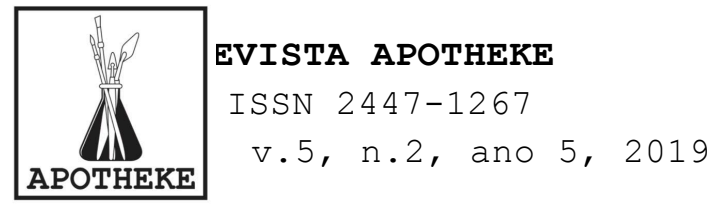

irreversivelmente perdida. 3 Assim, Kamenszain aponta para uma preservação deste espaço de experiência, que se manteve preservada, ainda que sutil e sub-repticiamente, frente às mudanças técnicas e estéticas da modernidade.

Nas palavras da própria Ana Hatherly,a incorporação subversiva dos gestos do passado no presente, fazem parte do campo da cultura e das artes:

A incorporação do passado no presente é uma acção subversiva, porque um dos efeitos mais surpreendentes da acção do tempo é transformar o usual em estranho, o conhecido em desconhecido, o ordinário em exótico. A incorporação de elementos antigos num contexto moderno rompe a continuidade, dispersa a continuidade nociva que conduz ao hábito, criando um conflito, um contraste, que não pode senão despertar o nosso consciente. Toda a cultura é diálogo e não há diálogo sem confrontação. (Hatherly:1995)

Uma das coisas que mais me impressionou nos desenhos de Ana Hatherly quando fui visitar o acervo da Fundação, foi constatar o quanto de minúcias e delicadeza havia em seus desenhos, mas muito mais especialmente nos trabalhos em que a palavra escrita faz parte. Da reciprocidade entre a escrita e a visualidade no trabalho de Ana Hatherly, surgem novas indagações sobre os limites disciplinares rompidos em nome de uma expressão artística que ao mesmo tempo cifra e desvela, finge ou simula, como é próprio das poéticas do barroco moderno e contemporâneo. Também pelos deslocamentos entre sujeito e objeto que a escrita e a arte permitem ou evidenciam.

\footnotetext{
3 Valeria a pena retomarmos algumas das noções colocadas ainda por Benjamin em Experiência e Pobreza: "Sabia-se exatamente o significado da experiência: ela sempre fora comunicada aos jovens. De forma concisa, com a autoridade da velhice, em provérbios; de forma prolixa, com a sua loquacidade, em histórias; muitas vezes como narrativas de países longínquos, diante da lareira contadas a pais e netos. Que foi feito de tudo isso? Quem encontra ainda pessoas que saibam contar histórias como elas devem ser contadas? Que moribundos dizem hoje palavras tão duráveis que possam ser transmitidas como um anel, de geração em geração? Quem é ajudado, hoje, por um provérbio oportuno? Quem tentará, sequer, lidar com a juventude invocando sua experiência?". Cf. Walter Benjamin. Obras escolhidas. p. 116.
} 

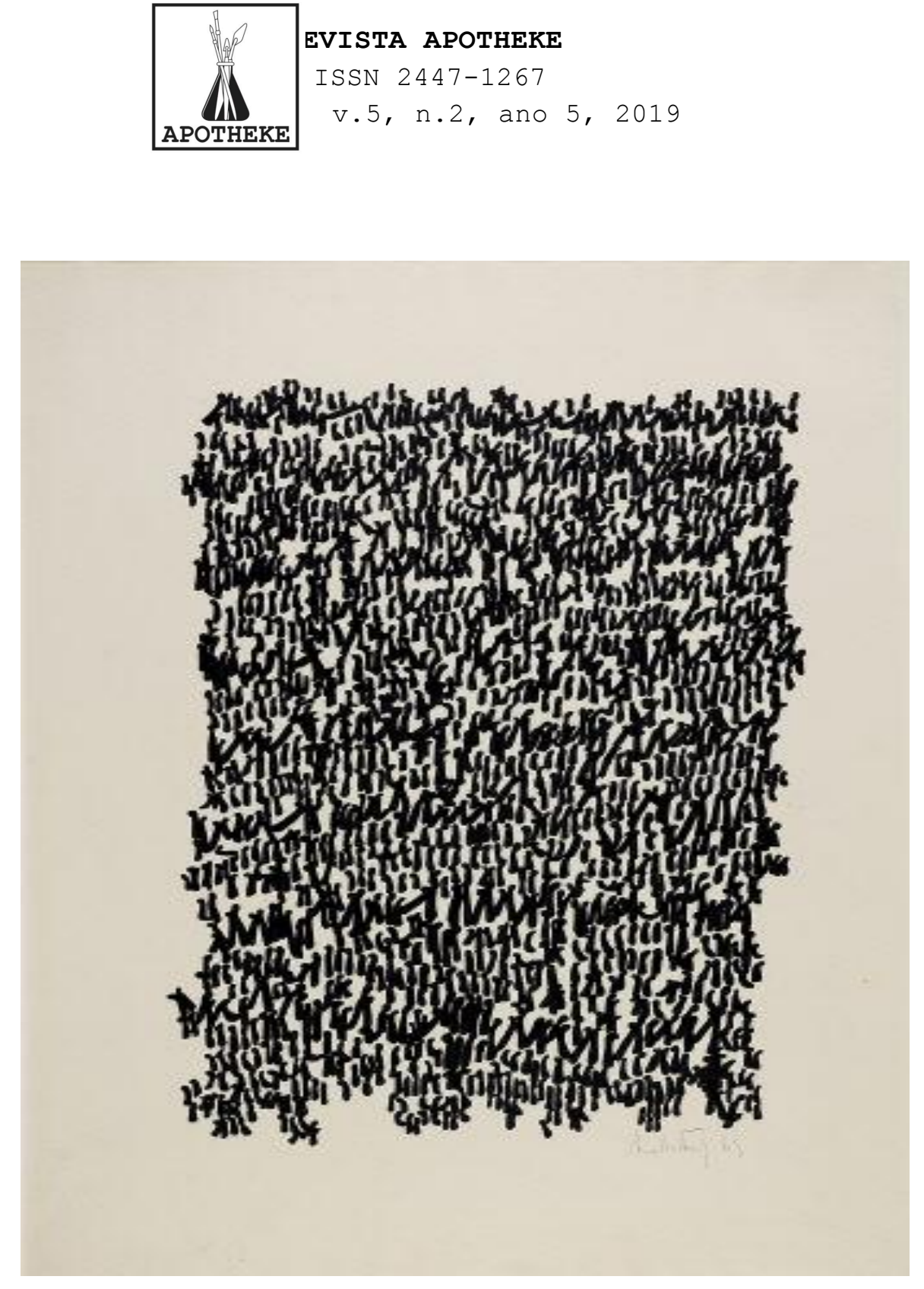

Ana Hatherly, S/título.Ponta de feltro sobre papel Fabriano, 1969 (acervo Gulbenkian) 

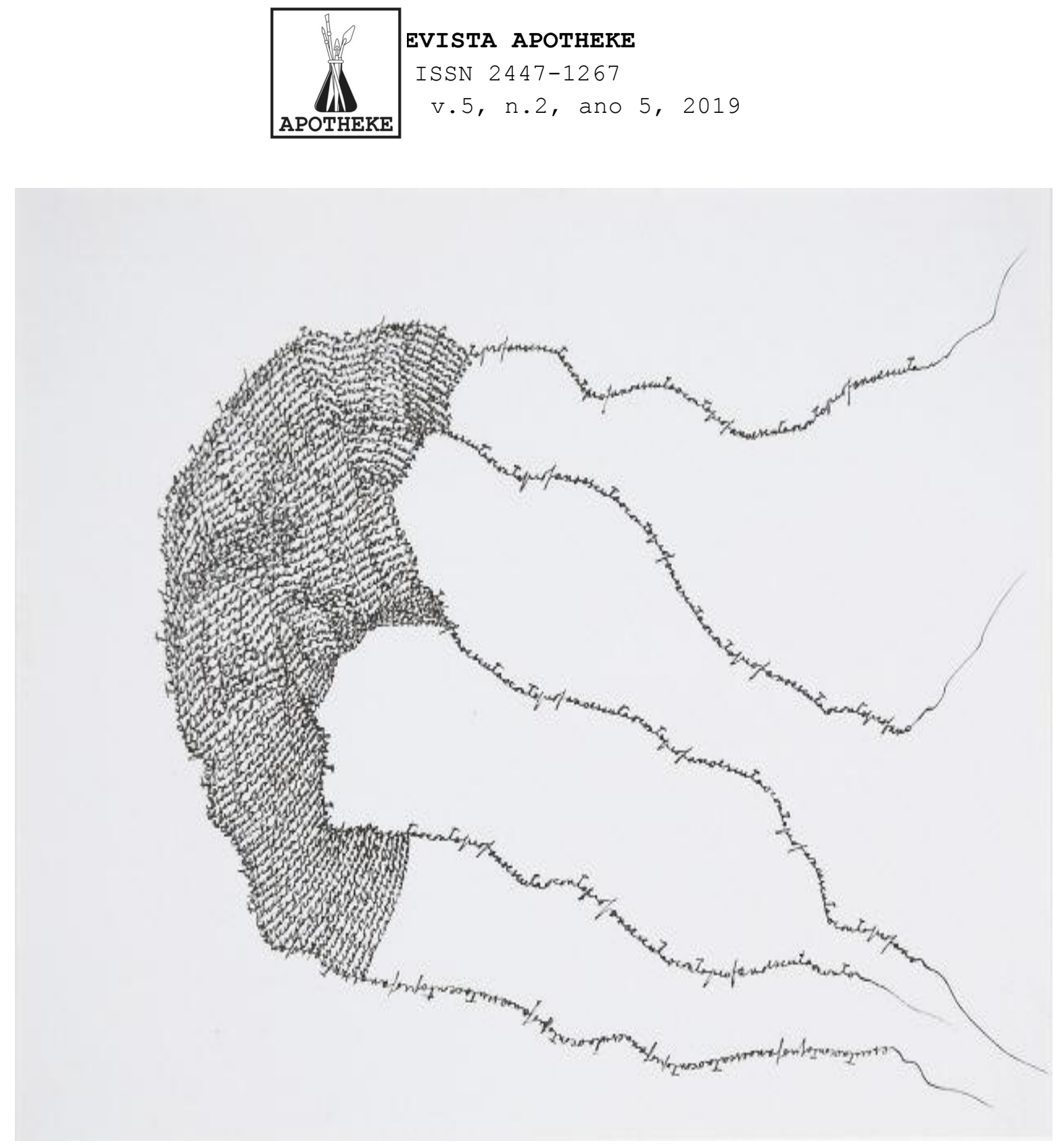

Ana Hatherly: "Escuta o conto profano". Nanquim sobre papel. 1998 (acervo Gulbenkian)

Mira Schendel, por razões singulares se aproxima do modo híbrido entre palavra e imagem presente na obra de Hatherly. Nascida em Zurique em 1919, Schendel viveu em Milão e Roma antes de emigrar para o Brasil em 1949. Primeiramente viveu em Porto Alegre, e em 1953, fixou-se em São Paulo, onde viveu e trabalhou até à sua morte, em 1988. A experiência precoce de deslocações culturais, geográficas e linguísticas e um profundo interesse pela história da religião e pela filosofia 


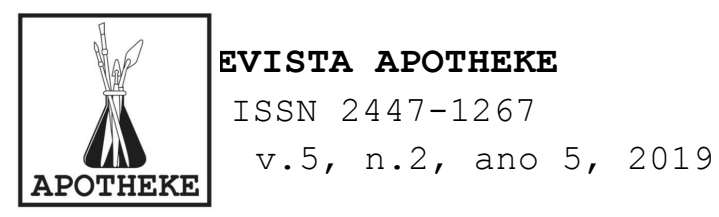

são uma marca permanente em sua vida e sua obra. A artista contribuiu para criar no Brasil um círculo de intelectuais oriundos diversos campos humanísticos como os da literatura, psicanálise, filosofia, teologia, dos quais, entre eles Vilém Flusser.eram judeus emigrados como ela, além disso, Mira manteve contato com importantes pensadores europeus, como Jean Gebser, Max Bense e Umberto Eco.

Não se tem aqui em espaço tão breve, como avaliar a profunda singularidade, vastidão e importância da obra e a variedade de temas e meios explorados pela artista. Mas resumidamente, pode-se perceber que suas primeiras pinturas (produzidas entre 1955/65), exibidas muito raramente, são reveladoras do confronto, que percorre o seu percurso, entre seus impulsos figurativos e complexas ordenações geométricas. A antológica e bem conhecida série das Droguinhas (1965/66, esculturas de papel de arroz originalmente expostas na signals Gallery, em Londres, em 1966, exemplificam uma tensão entre a fragilidade do material (papel), e a força com que são transmutados em esculturas. Apresentados pela primeira vez na Bienal de Veneza de 1968, os Objetos Gráficos evidenciam a sua peculiar singular abordagem de temas relacionados com a linguagem e o significado.

Sua condição nômade, a fazia se sentir estrangeira em qualquer lugar, estrangeira mesmo de si mesma. Seu sotaque e as diversas línguas que utilizava em sua vida e em sua arte reforçam essa condição. Numa época anterior à globalização, Mira usava o português brasileiro para as coisas do dia-a-dia, - alemão para as coisas da filosofia, o italiano para referir as coisas da infância, as línguas balcânicas com que contatou nas suas andanças de judia sem país durante a segunda Guerra Mundial e o inglês para outras eventualidades. Parece haver uma espécie de vontade de não pertencer a nenhum movimento, de 


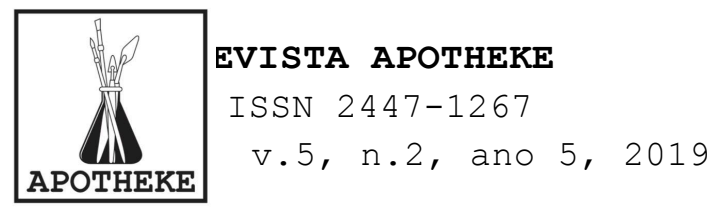

não aderir a nenhum manifesto, nesses primeiros anos da segunda metade do século $\mathrm{XX}$ em que a arte brasileira se dividia e subdividia em famílias. E, no entanto, apesar de ter estado sempre tão aparentemente à distância de tudo, ela também marcou o seu lugar. A própria Mira escreveu a Guy Brett, em 1965: "O que importa na minha obra é o vazio, ativamente o vazio" (Apud Stigger, 2018)). Segundo Veronica Stigger, há dois aspectos que podem nos ajudar a esclarecer a questão: as condições de vida de Mira Schendel na Europa antes de sua chegada ao Brasil, em 1949, e o próprio contexto político e social desta época. (Stigger: 2018) ${ }^{4}$

Temos em sua obra as letras em cima de letras, as palavras em cima de palavras, uma babel de línguas sobrepostas. Mira trabalha em palimpsesto, forçando transparências e sobreposições.

Era sobre poder constituidor da linguagem, mas também do seu colapso inevitável, que Mira Schendel verdadeiramente quis expressar em qualquer língua. Memória e esquecimento, aquilo que não se ouviu e que, no entanto existiu. E também do silêncio divino, que, no entanto diz coisas. Para ela, arte era outra maneira de falar de uma espécie nostalgia do sagrado, e de tudo o que é impossível.

\footnotetext{
4 Stigger, Veronica: 0 esvaziamento: Mira Schendel e a poesia da destruição.Academia. Edu. Nesse artigo, Stigger observa que pai de Mira era tchecoslovaco, de família judaica; e a mãe, filha de um alemão e de uma italiana, de origem judaica, mas convertida ao catolicismo. Os pais se separaram quando Mira era ainda bebê, e a mãe se casou novamente com um conde italiano. Durante a Segunda Guerra Mundial, Mira partiu de Milão para Sofia, na Bulgária, fugindo da perseguição nazista. Acabou em Sarajevo, na ex-Iugoslávia, onde se casou com Josip Hargesheimer com o intuito de conseguir permissão para emigrar. Em Roma, onde permaneceu entre 1946 e 1949 , foi taxada pelo governo de "pessoa deslocada" se tem muito mais notícia sobre o passado de Mira, antes de sua chegada ao Brasil, em 1949. Ela não falava sobre o assunto. Mas se desconfia que ela nunca tenha se sentido em casa em lugar algum.
} 


EVISTA APOTHEKE
ISSN 2447-1267
v.5, n.2, ano 5, 2019

OH

o

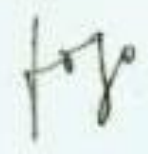
Th th th of ot ot

- $\quad f o p$ -FOGO
FOGO FOGO FOGO of ot

off

OI RUE NÁ SE OUVIN

O NOME

LU TUE NAO SE ONVIU

O NOME

$\sigma \quad \sigma$

OH FO6

of que nÁO SE OUVIV

- NOME

$\circ 0$

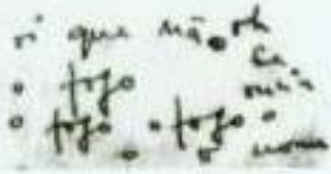

Mira Schendel: da série Escritos, tinta a óleo transferida para papel de arroz, 1965. 


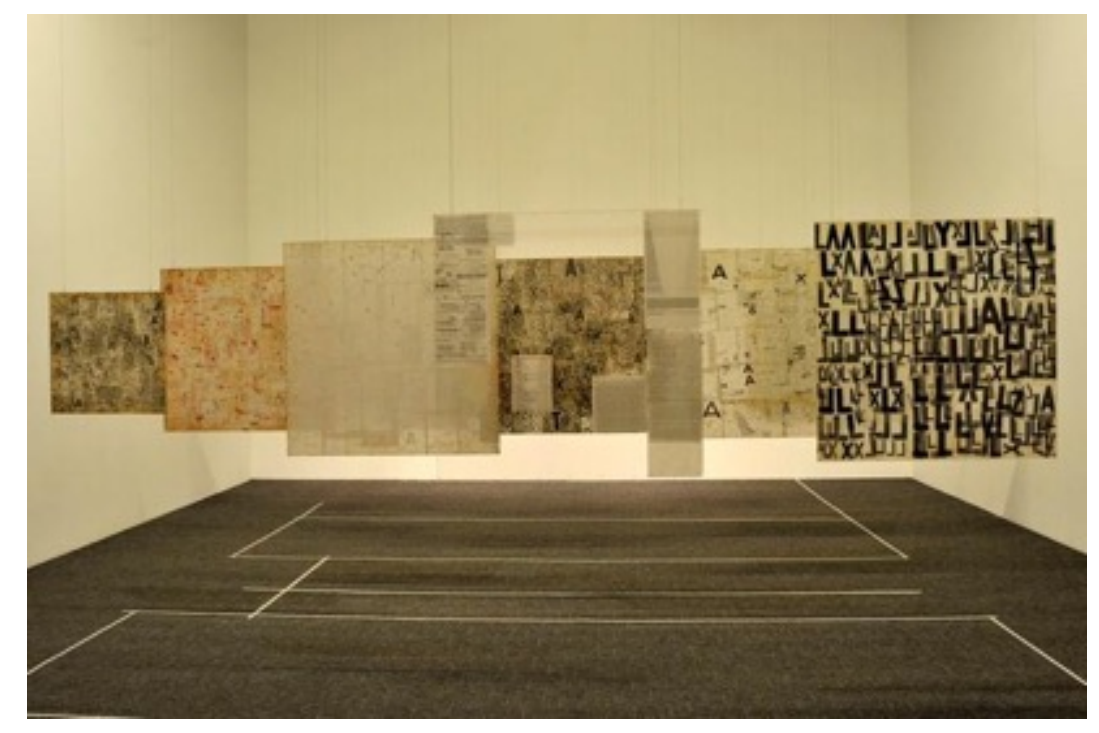

Mira Schendel. Objeto gráfico, c. 1967, decalque e óleo sobre papel de arroz e acrílico, 100 x 100 cm - Daros Latinamerica Collection, Zurique, Suíça.

De uma forma mais ampla, entre os artistas europeus que emigraram para o Brasil, durante e logo após a segunda guerra mundial, que contribuíram para a modernização das linguagens plásticas, o caso de Mira Schendel merece atenção especial no sentido de contribuir num campo ampliado das artes visuais, incluindo em sua obra questionamentos de ordem filosófica. Pois não é ainda uma obra plástica amadurecida que Mira ( que tinha trinta anos de idade quando emigrou)traz como bagagem expressiva, mas sim um arcabouço conceitual nutrido por inquietações filosófico-religiosas que se ampliam em contato com um meio cultural mais propenso ao estímulo da expressão artística, do que ao rigor do pensamento filosófico. Trabalhos experimentais e por vezes efêmeros que traduzem experimentação, produtos de suas investigações sobre a linguagem, a partir da relação entre a imagem e a palavra. A fragilidade percorre esse processo.. A delicadeza de seus trabalho remete à ordem do feminino no fazer das questões da arte. Em seu percurso alude às atividades tradicionalmente 
ligadas ao mundo da mulher, como na série bordados do início dos anos 60, em que reinterpreta meios artísticos mais tradicionais como tinta nanquim e papel artesanal, como fios de linha e tecidos de uma ocupação doméstica, ou nos gestos de trançar enrolar, e dar nós nas delicadas folhas de papel de arroz das droguinhas. Quando os textos surgem em sua obra, eles são integrados a outros componentes gráficos, as palavras ganham expressividade sensorial, transcendência e imanência, as vezes lembram mantras ou orações quando são transportado às folhas de papel de arroz, peças impressões monográficas.

Com essas obras Mira Schendel alcança um lugar da arte, de onde surge uma caligrafia imagística, na qual coincidem dois regimes da linguagem, 0 da imagem e 0 da palavra, identificando o conteúdo expressivo da caligrafia à verdade do conteúdo. A caligrafia pessoal e a imagem surgida do fluxo do pensamento produzem então uma relação de tempo e espaço fundada na palavra. 


EVISTA APOTHEKE
ISSN 2447-1267
V.5, n.2, ano 5, 2019

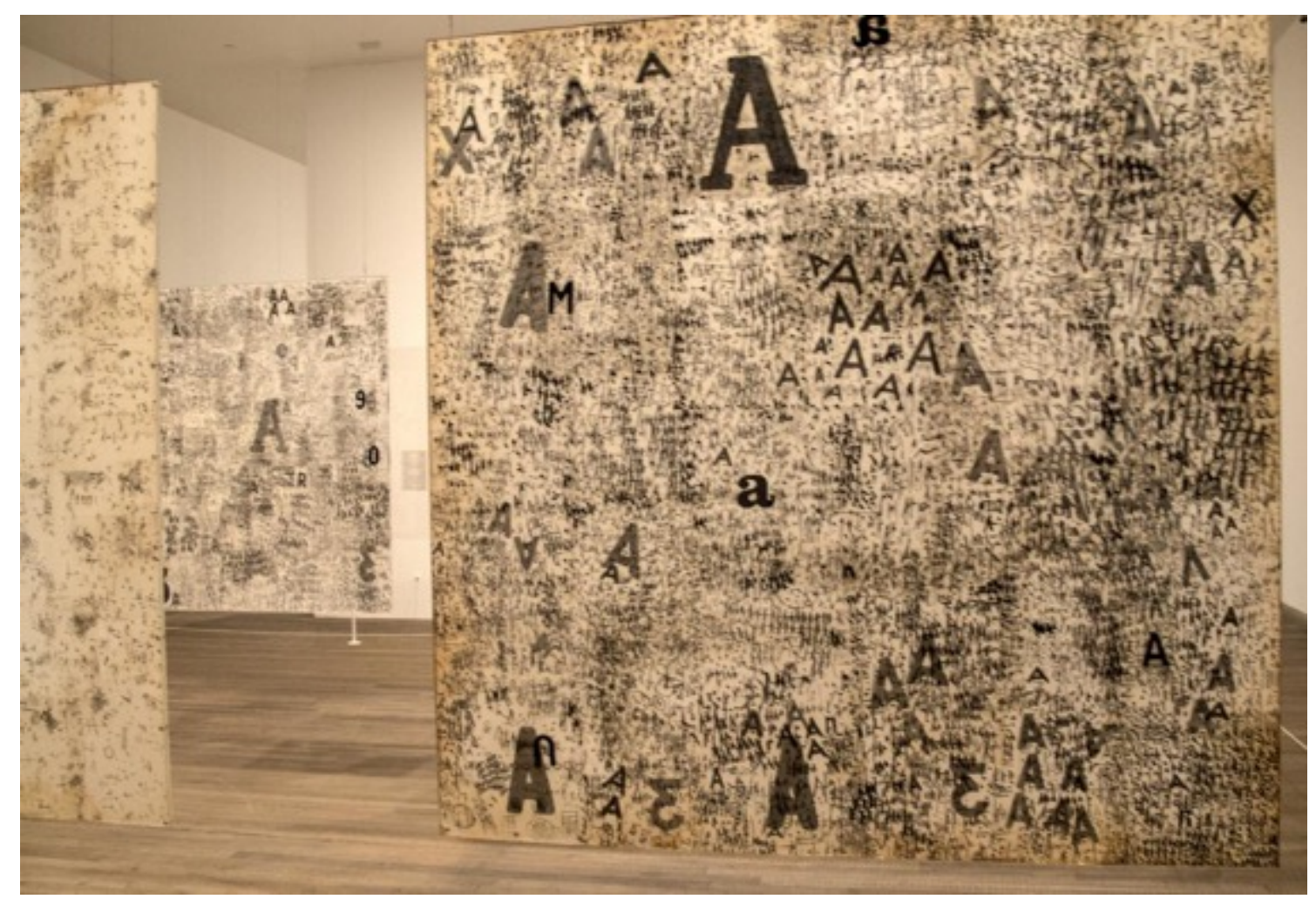

Mira Schendel. Pinturas suspensas nas duas faces. Óleo sobre papel de arroz. $1967 / 8$

Seus desenhos/monotipias de fundem a poesia com o espaço, e por isso apresentam similaridade tanto com a caligrafia oriental quanto com o abstracionismo pictórico informal. Com a escrita utilizada não apenas como meio elevado de expressão, mas também como anotação ligeira daquilo que poderia passar despercebido enquanto registro rotineiro, e que sua ação transformava em poesia, a artista eleva a gestualidade da letra.

Alguns de seus trabalhos não revelam nenhuma palavra ou frase: a escrita automática, o som das sílabas ou das vogais, são como uma desculpa para o movimento da mão sobre o papel. Assim se formam estruturas visuais complexas que soltas ou articuladas, invadem o espaço arquitetônico e que também foram utilizados por Mira Schendel para unir de forma 


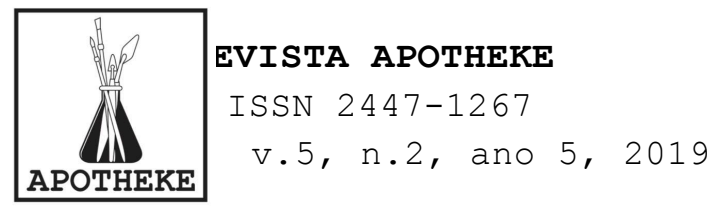

complementar, tempo e espaço. Trabalhos, que expressam um dinamismo visual próximo ao do barroco, e próximo ao trabalho desenvolvido também sob a cifra barroca de Ana Hatherly.

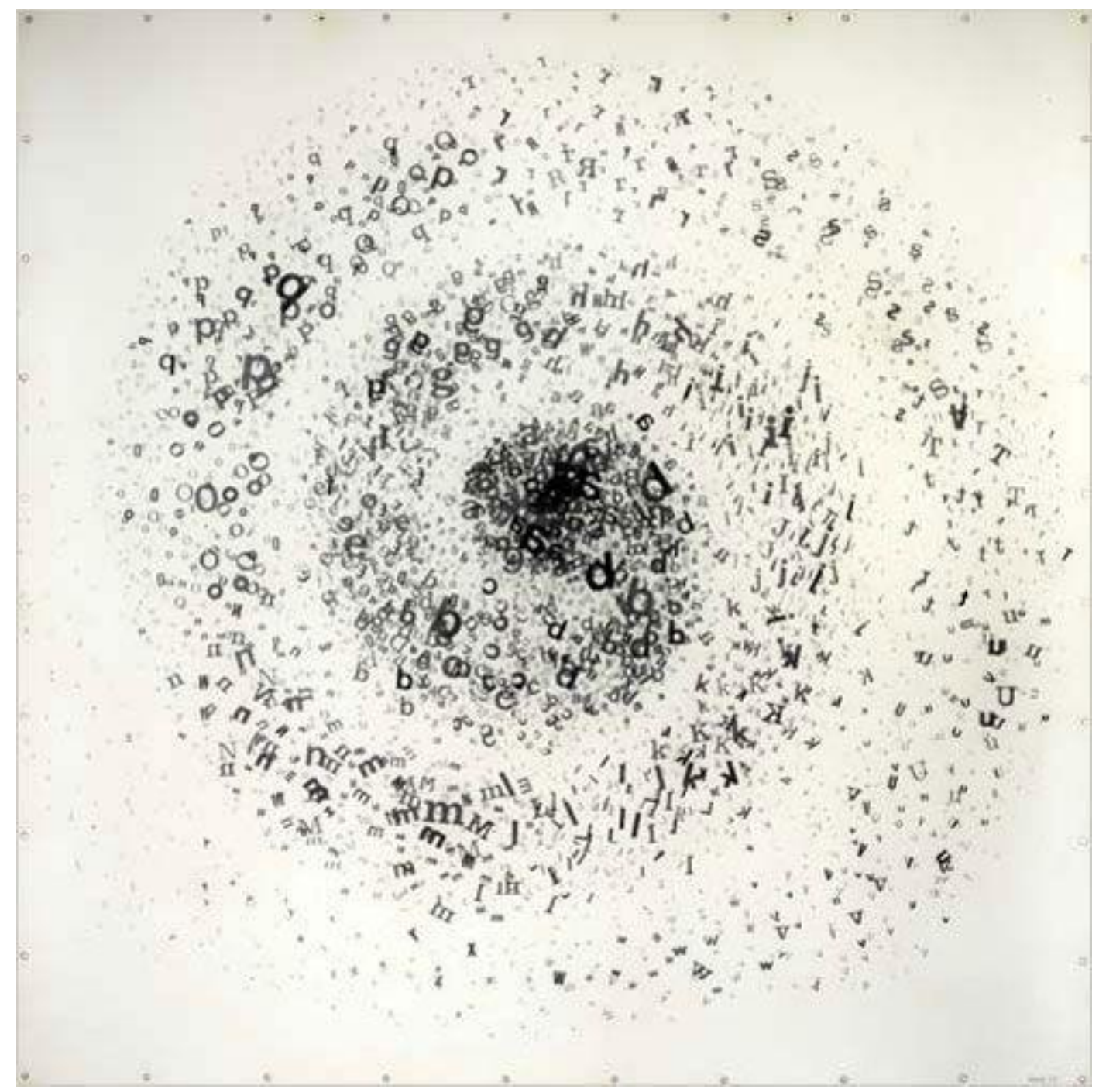

Mira Schendel: da série Objetos gráficos, 1972 (Coleção Clara Sankovski)

O gesto manual original dos sinais caligráficos como letras ou números sofre modificações com a introdução das letras autocolantes (Letraset) que proporcionaram aos desenhos um caráter plástico diferente, mais distanciado da fatura manual anterior, e representam a entrada de um elemento concreto num sistema de relações abstratas, já próprias de trabalhos anteriores de Mira Schendel. 


\begin{tabular}{l|l} 
EVISTA APOTHEKE \\
ISSN $2447-1267$ \\
v.5, n.2, ano 5, 2019
\end{tabular}

Na obra de Ana Hatherly e Mira schendel, os valores
singulares das letras, palavras, sentenças e breves
interpontuações, juntam-se para se transformarem em seres
híbridos, desenhos-poesia que, nos interstícios do papel,
assumem significados imprevistos e ainda mais abertos e
especulativos, legado que unem como uma ponte, a tradição ao
futuro.

\section{Referências :}

BATEL, Joana. In:https://gulbenkian.pt/museu/artist/ana-hatherly/ 2010 .

BENJAMIN, Walter. Experiencia e pobreza.In: obras escolhidas. Trad. Sergio Paulo Rouanet. 10. reimpr. São Paulo: Brasiliense, 1996. v. 1: magia e técnica, arte e política.

HATHERRLY, Ana. A casa das musas. Lisboa: Editorial Estampa, 1995.

KAMENZAIN, Tamara. Tâmara. Bordado y costura del texto.in: Historia de amor (y otros ensayos sobre poesía). Buenos Aires: Paidós, 2002. pp. $205 / 211$.

MARTINS, Marta.Quase coisa nenhuma. Fpólis: Cultura\&barbárie, 2018

PIRES do VALE, Paulo. Ana Hetherly e o Barroco, Num jardim feito de tinta. Lisboa, Fundação Calouste Gulbenkian, 2017

STIGGER, Veronica: 0 esvaziamento: Mira Schendel e a poesia da destruição.Academia. Edu. 2018

Marta Lúcia Pereira Martins é graduada em Educação Artística pela Universidade do Estado de Santa Catarina (1988), Mestra em Artes Visuais pela Universidade Federal do Rio Grande do Sul (1995) e Doutora em Literatura pela Universidade Federal de Santa Catarina (2005). É professora no Curso de Artes Visuais da Universidade do Estado de Santa Catarina atuando na Graduação e no PPGAV nas seguintes áreas: Desenho, Teoria da Modernidade, Literatura, Arte Contemporânea, Teoria da Imagem, História e Crítica da Arte e Fotografia. É artista visual, ensaísta, narradora de ficção e fotógrafa. Foi premiada por Edital da Funarte na categoria de Estímulo a produção crítica, em 2012. Publicou "Narrativas ficcionais de Tunga", pela Editora Apicuri do RJ em 2013 e "Quase coisa nenhuma", pela Cultura\&Barbárie de Florianópolis em 2018.Fez pós doutorado na Faculdade de Ciências Sociais e Humanas da Universidade Nova de Lisboa em 2018 .

Endereço eletrônico do lattes: http://lattes.cnpq.br/2979880140598453

Recebido em 13 de maio de 2019. Aprovado em 17 de agosto de 2019. 